\title{
Preferential benefits of nifedipine GITS in systolic hypertension and in combination with RAS blockade: further analysis of the 'ACTION' database in patients with angina
}

\author{
HL Elliott ${ }^{1}$ and PA Meredith ${ }^{2}$ \\ ${ }^{1}$ Institute of Pharmaceutical and Biomedical Sciences, University of Strathclyde, Glasgow, UK and ${ }^{2}$ Division \\ of Cardiovascular and Medical Sciences, University of Glasgow, The Western Infirmary, Glasgow, UK
}

\begin{abstract}
A retrospective analysis of the database from A Coronary Disease Trial Investigating Outcome with Nifedipine (ACTION) evaluated the effectiveness of nifedipine gastrointestinal therapeutic system (GITS) (i) in combination with renin angiotensin system (RAS) blockers and (ii) in patients with isolated systolic hypertension (ISH). Analysed on an intention-to-treat basis, treatment groups were compared by the log-rank test without adjustment for covariates and hazard ratios with $95 \%$ Cls were obtained using Cox proportional hazards models. Of 7665 randomized patients, 1732 patients were receiving RAS blockade at baseline, the addition of nifedipine GITS significantly reduced any cardiovascular (CV) event $(-20 \% ; P<0.05)$, the composite of death, any CV event and revascularization $(-16 \% ; P<0.05)$ and coronary angiography $(-22 \%$;
\end{abstract}

$\boldsymbol{P}<0.01$ ). These benefits were achieved with relatively small differences in systolic $(3.2 \mathrm{~mm} \mathrm{Hg})$ and diastolic blood pressure (BP) $(2.3 \mathrm{~mm} \mathrm{Hg})$. In 2303 patients $(30.0 \%)$ who had ISH at baseline (1145 nifedipine GITS and 1158 placebo), nifedipine significantly reduced the primary efficacy end point $(-18 \% ; P<0.03)$, any CV event $(-22 \%$; $P<0.01)$ and new heart failure $(-40 \% ; P<0.01)$. The benefits were associated with between-group differences in achieved BP of 4.7 and $3.3 \mathrm{~mm} \mathrm{Hg}$ for systolic and diastolic BP, respectively. In summary, the lowest CV event rates were seen in those receiving (i) the combination of RAS blockade and nifedipine GITS and (ii) in those specifically treated for ISH.

Journal of Human Hypertension (2011) 25, 63-70; doi:10.1038/jhh.2010.19; published online 25 February 2010

Keywords: ACE inhibitor; angiotensin receptor blockers; combination drug therapy; coronary artery disease; isolated systolic hypertension; nifedipine

\section{Introduction}

Hypertension is a powerful and independent risk factor for all clinical manifestations of atheromatous cardiovascular (CV) disease including coronary artery disease (CAD), stroke, peripheral vascular disease and heart failure. Globally, these major vascular diseases are projected to remain leading causes of morbidity and mortality until at least $2030 .^{1-3}$ Although a number of clinical outcome trials have shown that antihypertensive drug treatment, either as monotherapy or combination therapy, is particularly beneficial in patients with high CV risk there is relatively little specific information about the treatment of patients with hypertension and angina.

Correspondence: Dr PA Meredith, Division of Cardiovascular and Medical Sciences, University of Glasgow, Gardiner Institute, The Western Infirmary, Glasgow G11 6NT, Scotland, UK.

E-mail: pam1v@clinmed.gla.ac.uk

Received 14 November 2009; accepted 23 January 2010; published online 25 February 2010
The drug treatment of $\mathrm{CV}$ diseases, including hypertension and angina, is continually evolving and refining in response to new information. For example, in recent years and across the whole spectrum of CAD and its sequelae, there has been an increasing emphasis on the use of drugs that block the renin angiotensin system (RAS) and ACE inhibitor drugs are now recommended in the treatment of angina even though they have no intrinsic anti-anginal activity. Correspondingly, in the treatment of hypertension there is increasing emphasis on the use of combination treatments ${ }^{4}$ and on the importance of systolic blood pressure (BP) as a treatment target. $^{5}$ With regard to the optimal management of the patient with both hypertension and angina a number of different targets require to be addressed. These include

(i) risk factor modification, including $\mathrm{BP}$ control to $<130 / 80 \mathrm{~mm} \mathrm{Hg}$;

(ii) symptomatic improvement, that is reduced frequency of anginal episodes and reduced 
intake of other medications, particularly shortacting nitrates;

(iii) prognostic improvement-for example, reduced morbidity (interventions and events) and improved mortality.

Nifedipine is a well-established dihydropyridine calcium channel blocker (CCB) that is widely used for the treatment of hypertension and other CV diseases. The gastrointestinal therapeutic system (GITS) is a long-acting formulation of this compound that has been studied in a number of clinical trials. In one large randomized outcome trial in hypertensive patients (INSIGHT), nifedipine GITS was compared with co-amilozide and found to be equally effective in preventing overall cardioand cerebro-vascular complications. ${ }^{6}$ The placebocontrolled ACTION (A Coronary Disease Trial Investigating Outcome with Nifedipine GITS) trial examined the effects of the same compound on clinical outcomes in patients with stable symptomatic CAD. The principal conclusions were that nifedipine GITS not only is safe in patients with stable symptomatic coronary disease but also significantly reduces the occurrence of new overt heart failure and the need for coronary interventions. ${ }^{7}$ Furthermore, in a subgroup analysis of the hypertensive patients, who constituted $52 \%$ of the ACTION study population, there were significantly fewer morbid events and procedures in the patients receiving nifedipine GITS. ${ }^{8}$

The substantial clinical database from the ACTION study has afforded the opportunity to specifically address some further, clinically relevant issues by way of retrospective analysis. In particular, the usefulness and effectiveness of treatment with nifedipine GITS has been appraised with specific respect to the management of patients with angina and the following issues:

(i) Antihypertensive and outcome effectiveness of nifedipine GITS in combination with drugs, which block the RAS blockade.

(ii) Patients with isolated systolic hypertension (ISH).

\section{Patients and methods}

The design, methods and main results of the ACTION trial have been published in detail previously. $^{7,9}$ In brief, 7655 patients with angina pectoris were randomized to receive either nifedipine GITS $(n=3825)$ or matching placebo (3840). In addition to angina, patients had to have either a history of myocardial infarction, or proven angiographic CAD or a positive exercise test or perfusion defect. The left ventricular ejection fraction had to be at least $40 \%$. Detailed selection criteria and definitions have been described elsewhere. ${ }^{9}$ The starting dose of nifedipine GITS or placebo was $30 \mathrm{mg}$ once daily, increasing to $60 \mathrm{mg}$ once daily within 6 weeks. It is important to note that these treatments were in addition to 'best practice' CV therapy, with a follow-up period of almost 5 years.

This further analysis has explored the effectiveness of treatment with nifedipine GITS on the following clinical problems:

(i) The combination of calcium channel blockade (with nifedipine) and RAS blockade (with ACE inhibitor drugs or angiotensin receptor blocking drugs).

(ii) ISH (systolic $\mathrm{BP}>140$ and diastolic $\mathrm{BP}$ $<90 \mathrm{~mm} \mathrm{Hg}$ ).

\section{Statistical methods}

The following composite outcomes were compared: the combined rate of death from any cause, myocardial infarction, refractory angina requiring coronary angiography, new overt heart failure requiring hospitalization and peripheral revascularization (that is the ACTION primary end point for efficacy); the combined rate of death from any cause, myocardial infarction and debilitating stroke (that is the ACTION primary end point for safety); any CV event (that is the ACTION primary end point for efficacy minus non-CV death); any death, CV event or procedure (that is the ACTION primary end point for efficacy plus coronary angiography, percutaneous coronary intervention and coronary bypass surgery); and any vascular event or procedure (that is the ACTION primary end point for efficacy minus non-CV death and new overt heart failure, plus percutaneous coronary intervention and coronary bypass surgery).

All analyses for composite outcomes and clinical events were performed on an intention-to-treat basis. Deaths of unknown cause were considered as CV. Coronary angiography and percutaneous coronary intervention on the same day were counted only as percutaneous coronary intervention. Treatment groups were compared by the log-rank test without adjustment for covariates or interim analysis. Hazard ratios with 95\% confidence intervals were obtained using Cox proportional hazards models with treatment allocation as the only covariate.

\section{Results}

Combination of calcium channel blockade and RAS blockade

Of 7665 patients started on study medication, 1732 $(22.6 \%)$ were receiving RAS blockade (ACE inhibitor or ARB) at baseline and 857 were randomized to receive nifedipine GITS and 875 to placebo. The baseline characteristics of these patients are given in Table 1 and the data on the use of additional BP lowering medication at baseline are given in Table 2 . The BP responses at baseline and at the end of follow-up in the trial are given in Table 3. Figure 1, shows the effects of nifedipine (relative to placebo) 
Table 1 Clinical characteristics of patients with RAS blockade

\begin{tabular}{|c|c|c|}
\hline & $\begin{array}{l}\text { Nifedipine } \\
(\mathrm{n}=857)\end{array}$ & $\begin{array}{l}\text { Placebo } \\
(\mathrm{n}=875)\end{array}$ \\
\hline \multicolumn{3}{|l|}{ Demographics } \\
\hline Age (years) & $63.8 \pm 8.8$ & $63.7 \pm 9.2$ \\
\hline Men & $75.8 \%$ & $76.6 \%$ \\
\hline \multicolumn{3}{|l|}{ Clinical features } \\
\hline History of myocardial infarction & $56.6 \%$ & $57.5 \%$ \\
\hline With coronary revascularization & $27.5 \%$ & $29.5 \%$ \\
\hline $\begin{array}{l}\text { Angiographic coronary artery } \\
\text { disease, no myocardial infarction }\end{array}$ & $30.0 \%$ & $30.2 \%$ \\
\hline With coronary revascularization & $17.5 \%$ & $17.8 \%$ \\
\hline $\begin{array}{l}\text { Positive exercise or radionuclide } \\
\text { test only }\end{array}$ & $13.2 \%$ & $12.0 \%$ \\
\hline No history of coronary artery disease & $0.2 \%$ & $0.3 \%$ \\
\hline $\begin{array}{l}\text { Significant lesions on coronary } \\
\text { angiogram }\end{array}$ & $72.3 \%$ & $73.0 \%$ \\
\hline Past use of calcium antagonists & $23.8 \%$ & $20.8 \%$ \\
\hline Current NYHA classes II-III & $45.4 \%$ & $42.6 \%$ \\
\hline Anginal attacks & $92.5 \%$ & $91.9 \%$ \\
\hline $\begin{array}{l}\text { History of peripheral cardiovascular } \\
\text { disease }\end{array}$ & $18.5 \%$ & $17.0 \%$ \\
\hline \multicolumn{3}{|l|}{ Risk factors } \\
\hline Current smoker & $15.2 \%$ & $14.3 \%$ \\
\hline Total cholesterol $\geqslant 5.0 \mathrm{mmol}^{-1}$ & $61.4 \%$ & $64.7 \%$ \\
\hline Body mass index $\geqslant 30.0 \mathrm{~kg} \mathrm{~m}^{-2}$ & $27.8 \%$ & $27.1 \%$ \\
\hline Diabetes mellitus & $22.7 \%$ & $23.0 \%$ \\
\hline Treated with insulin & $4.6 \%$ & $5.7 \%$ \\
\hline \multicolumn{3}{|l|}{ Cardiovascular variables } \\
\hline Heart rate (beats per min) & $65.8 \pm 10.5$ & $66.8 \pm 10.9$ \\
\hline Systolic blood pressure (mm Hg) & $142.7 \pm 20.0$ & $143.1 \pm 18.9$ \\
\hline Diastolic blood pressure (mm Hg) & $82.4 \pm 9.5$ & $82.0 \pm 9.4$ \\
\hline
\end{tabular}

Abbreviation: RAS, renin angiotensin system.

on pre-defined ACTION combined end points in patients receiving RAS blockade at baseline. The salient results are also provided in summary table in comparison with those of the whole study population (Table 4).

As evidenced by $95 \%$ confidence intervals that do not include 'no effect' (hazard ratio=1), nifedipine significantly reduced any $\mathrm{CV}$ event, the composite of death, any CV event and revascularization and coronary angiography, in patients receiving RAS blockade at baseline (Figure 1). There were also reductions in the primary composite end points for both efficacy and safety, by, respectively, 14 and $7 \%$, but these did not achieve statistical significance. These benefits were achieved despite relatively small differences between the groups in achieved BP: by 3.2 for systolic and by $2.3 \mathrm{~mm} \mathrm{Hg}$ for diastolic BP (Table 3). The achieved BP differences were less than those in the overall study population but numerically all of the benefits with nifedipine GITS were greater in the patients receiving RAS blockade at baseline (Table 4).

\section{Isolated systolic hypertension}

Of 7665 patients started on study medication, $2303(30.0 \%)$ had ISH at baseline and 1145 were
Table 2 Use of concomitant treatments at baseline in patients with RAS blockade

\begin{tabular}{lcc}
\hline & $\begin{array}{c}\text { Nifedipine } \\
(\mathrm{n}=857)\end{array}$ & $\begin{array}{c}\text { Placebo } \\
(\mathrm{n}=875)\end{array}$ \\
\hline Antianginal drug & $71.7(\%)$ & $72.9(\%)$ \\
$\beta$ blocker & $48.0(\%)$ & $48.9(\%)$ \\
Organic nitrate, as needed & $41.0(\%)$ & $39.8(\%)$ \\
Organic nitrate, daily maintenance & $5.7(\%)$ & $5.7(\%)$ \\
Other vasodilator & $97.8(\%)$ & $97.9(\%)$ \\
Any of the above & $44.2(\%)$ & $45.6(\%)$ \\
Any two of the above & $11.8(\%)$ & $11.6(\%)$ \\
Any three or four of the above & & \\
& & \\
Lipid lowering & $62.0(\%)$ & $63.1(\%)$ \\
Statin & $7.9(\%)$ & $7.5(\%)$ \\
Fibrate & $0.9(\%)$ & $1.4(\%)$ \\
Other & $68.8(\%)$ & $69.2(\%)$ \\
Any of the above & & \\
Blood pressure lowering & $89.7(\%)$ & $89.9(\%)$ \\
ACE inhibitor & $10.3(\%)$ & $10.1(\%)$ \\
Angiotensin-II antagonist & $20.3(\%)$ & $23.3(\%)$ \\
Diuretic & $3.6(\%)$ & $2.5(\%)$ \\
Other & $100(\%)$ & $100(\%)$ \\
Any of the above & & \\
Other cardiovascular & & \\
Acetylsalicylic acid & & \\
Vitamin K antagonist & & \\
Cardiac glycoside & & \\
Amiodarone, sotalol or other & & \\
antiarrhythmic & $4.4(\%)$ & $84.8(\%)$ \\
& & $5.1(\%)$ \\
\hline
\end{tabular}

Abbreviation: RAS, renin angiotensin system.

Table 3 The BP responses to nifedipine and placebo in patients receiving RAS blockade (visit $18=4$ years treatment)

\begin{tabular}{lcccc}
\hline & Nifedipine & Placebo & Nifedipine & Placebo \\
& SBP & SBP & DBP & DBP \\
\hline Visit 0 & $n=857$ & $n=875$ & $n=857$ & $n=875$ \\
Mean & $142.7 \pm 19.9$ & $143.1 \pm 18.9$ & $82.4 \pm 9.5$ & $82.1 \pm 9.4$ \\
Visit 18 & $n=679$ & $n=699$ & $n=679$ & $n=699$ \\
Mean & $135.2 \pm 18.5$ & $139.0 \pm 18.9$ & $77.5 \pm 9.4$ & $79.5 \pm 9.7$ \\
Mean & $-7.0 \pm 22.0$ & $-3.8 \pm 21.0$ & $-4.8 \pm 11.2$ & $-2.5 \pm 11.2$ \\
difference & & & & \\
\hline
\end{tabular}

Abbreviations: BP, blood pressure; RAS, renin angiotensin system.

randomized to receive nifedipine GITS and 1158 to placebo. The baseline characteristics of these patients are given in Table 5 and the data on the use of additional BP lowering medication at baseline are given in Table 6 . The BP responses at baseline and at the end of follow-up in the trial are given in Table 7. Figure 2 shows the effects of nifedipine (relative to placebo) on pre-defined ACTION combined end points in patients with ISH at baseline. The salient results are also summarized in Table 4 in comparison with those of the whole study population.

As evidenced by $95 \%$ confidence intervals that do not include 'no effect' (hazard ratio=1) (Figure 2), nifedipine significantly reduced the hazard of most of the combined end points. There were also 
reductions in the primary end point for safety (by 11\%) and in debilitating stroke (by 16\%) but these did not achieve statistical significance. These benefits were associated with differences between the groups in achieved BP: by 4.7 for systolic and by $3.3 \mathrm{~mm} \mathrm{Hg}$ for diastolic BP (Table 7). The achieved BP differences were comparable with those in the overall study population but the magnitude of the achieved benefit was greater in the patients with ISH (Table 4).

\section{Discussion}

The salient findings from these further analyses are that, relative to the ACTION population as a whole, the lowest rates for CV events were seen when treatment with nifedipine GITS was (i) combined with RAS blockade and (ii) applied to patients with ISH. Of themselves these findings are perhaps

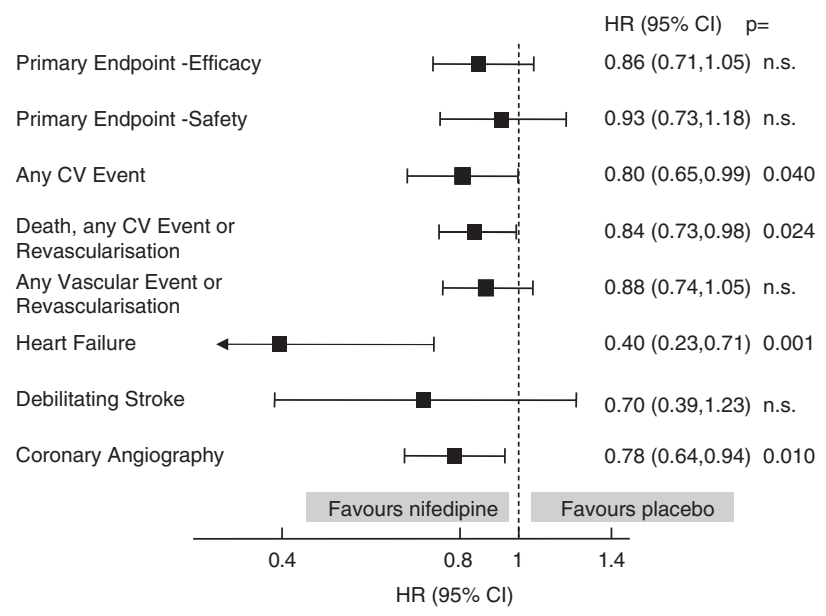

Figure 1 The effect of nifedipine GITS on pre-defined end points in patients receiving RAS blockade at baseline. not surprising, particularly to the hypertension specialists, but the relevance of 'tight' control of (systolic) BP and the requirement in this patient population for other agents in addition to ACE inhibition appear to be only slowly influencing

Table 5 Clinical characteristics of patients with isolated systolic hypertension

\begin{tabular}{|c|c|c|}
\hline & $\begin{array}{l}\text { Nifedipine } \\
(\mathrm{n}=1145)\end{array}$ & $\begin{array}{l}\text { Placebo } \\
(\mathrm{n}=1158)\end{array}$ \\
\hline \multicolumn{3}{|l|}{ Demographics } \\
\hline Age (years) & $66.8 \pm 8.2$ & $66.3 \pm 8.6$ \\
\hline Men & $74.4 \%$ & $73.7 \%$ \\
\hline \multicolumn{3}{|l|}{ Clinical features } \\
\hline History of myocardial infarction & $49.3 \%$ & $45.0 \%$ \\
\hline With coronary revascularization & $22.8 \%$ & $22.9 \%$ \\
\hline $\begin{array}{l}\text { Angiographic coronary artery disease, } \\
\text { no myocardial infarction }\end{array}$ & $32.7 \%$ & $34.5 \%$ \\
\hline With coronary revascularization & $21.0 \%$ & $22.1 \%$ \\
\hline $\begin{array}{l}\text { Positive exercise or radionuclide test } \\
\text { only }\end{array}$ & $17.7 \%$ & $19.6 \%$ \\
\hline No history of coronary artery disease & $0.3 \%$ & $0.8 \%$ \\
\hline $\begin{array}{l}\text { Significant lesions on coronary } \\
\text { angiogram }\end{array}$ & $65.5 \%$ & $66.2 \%$ \\
\hline Past use of calcium antagonists & $23.6 \%$ & $23.3 \%$ \\
\hline Current NYHA classes II-III & $46.8 \%$ & $49.1 \%$ \\
\hline Anginal attacks & $92.7 \%$ & $92.7 \%$ \\
\hline $\begin{array}{l}\text { History of peripheral cardiovascular } \\
\text { disease }\end{array}$ & $18.4 \%$ & $18.7 \%$ \\
\hline \multicolumn{3}{|l|}{ Risk factors } \\
\hline Current smoker & $14.7 \%$ & $14.2 \%$ \\
\hline Total cholesterol $\geqslant 5.0 \mathrm{mmol}^{-1}$ & $63.2 \%$ & $61.9 \%$ \\
\hline Body-mass index $\geqslant 30.0 \mathrm{~kg} \mathrm{~m}^{-2}$ & $22.8 \%$ & $23.9 \%$ \\
\hline Diabetes mellitus & $19.9 \%$ & $17.5 \%$ \\
\hline Treated with insulin & $2.1 \%$ & $3.9 \%$ \\
\hline \multicolumn{3}{|l|}{ Cardiovascular variables } \\
\hline Heart rate (beats per min) & $64.1 \pm 10.3$ & $64.1 \pm 10.2$ \\
\hline Systolic blood pressure (mm Hg) & $148.9 \pm 10.5$ & $150.0 \pm 11.1$ \\
\hline Diastolic blood pressure (mm Hg) & $79.0 \pm 5.7$ & $79.1 \pm 6.0$ \\
\hline
\end{tabular}

Table 4 Relative incidence of end points (nifedipine vs placebo) compared to the overall patient population in ACTION in patients (A) receiving RAS blockade and (B) with isolated systolic hypertension (ISH)

\begin{tabular}{|c|c|c|c|}
\hline & $\begin{array}{c}(A) A C E I / A R B \\
\text { patients }(\mathrm{n}=1732)\end{array}$ & $\begin{array}{c}\text { ACTION } \\
\text { patients }(\mathrm{n}=7655)\end{array}$ & $\begin{array}{l}\text { (B) ISH patients } \\
(\mathrm{n}=2343)\end{array}$ \\
\hline Primary end point & $-14 \%(\mathrm{NS})$ & $-3 \%(\mathrm{NS})$ & $-18 \%(P<0.03)$ \\
\hline \multicolumn{4}{|l|}{ Secondary end points } \\
\hline Any CV event & $-20 \%(P<0.05)$ & $-6 \%(\mathrm{NS})$ & $-22 \%(P<0.01)$ \\
\hline CV event, death, procedure & $-16 \%(P<0.05)$ & $-11 \%(P<0.02)$ & $-16 \%(P<0.01)$ \\
\hline CV event, procedure & $-12 \%(\mathrm{NS})$ & $-9 \%(P<0.03)$ & $-18 \%(P<0.01)$ \\
\hline \multicolumn{4}{|l|}{ Individual end points } \\
\hline $\mathrm{BP}$ reduction $(\mathrm{mm} \mathrm{Hg})$ & $3.2 / 2.3$ & $4.6 / 2.7$ & $4.7 / 3.3$ \\
\hline New heart failure & $-60 \%(P<0.002)$ & $-29 \%(P<0.015)$ & $-40 \%(P<0.01)$ \\
\hline Debilitating stroke & $-30 \%$ (NS) & $-22 \%(\mathrm{NS})$ & $-16 \%$ (NS) \\
\hline Coronary angiography & $-22 \%(P<0.01)$ & $-18 \%(P<0.0001)$ & $-17 \%(P<0.03)$ \\
\hline Refractory angina & $-15 \%(\mathrm{NS})$ & $-14 \%(\mathrm{NS})$ & $-23 \%(<\mathrm{NS})$ \\
\hline
\end{tabular}

Abbreviations: ACTION, A Coronary Disease Trial Investigating Outcome with Nifedipine; BP, blood pressure; CV, cardiovascular; RAS, renin angiotensin system. 
Table 6 Use of concomitant treatments at baseline in patients with isolated systolic hypertension

\begin{tabular}{lcc}
\hline & $\begin{array}{c}\text { Nifedipine } \\
(\mathrm{n}=1145)\end{array}$ & $\begin{array}{c}\text { Placebo } \\
(\mathrm{n}=1158)\end{array}$ \\
\hline Antianginal drug & & \\
$\beta$ blocker & $78.4(\%)$ & $79.5(\%)$ \\
Organic nitrate, as needed & $58.2(\%)$ & $56.1(\%)$ \\
Organic nitrate, daily maintenance & $36.9(\%)$ & $37.0(\%)$ \\
Other vasodilator & $4.4(\%)$ & $3.7(\%)$ \\
Any of the above & $98.6(\%)$ & $98.3(\%)$ \\
Any two of the above & $51.3(\%)$ & $51.6(\%)$ \\
Any three or four of the above & $13.9(\%)$ & $13.1(\%)$ \\
& & \\
Lipid lowering & & \\
Statin & $60.0(\%)$ & $57.4(\%)$ \\
Fibrate & $5.6(\%)$ & $6.5(\%)$ \\
Other & $0.7(\%)$ & $1.3(\%)$ \\
Any of the above & $65.1(\%)$ & $63.0(\%)$ \\
Blood pressure lowering & & \\
ACE inhibitor & & \\
Angiotensin-II antagonist & $21.8(\%)$ & $23.8(\%)$ \\
Diuretic & $3.0(\%)$ & $3.5(\%)$ \\
Other & $15.0(\%)$ & $14.2(\%)$ \\
Any of the above & $2.8(\%)$ & $1.8(\%)$ \\
& $34.9(\%)$ & $35.6(\%)$ \\
Other cardiovascular & & \\
Acetylsalicylic acid & & \\
Vitamin K antagonist & & \\
Cardiac glycoside & $83.8(\%)$ & $83.9(\%)$ \\
Amiodarone, sotalol or other & $4.9(\%)$ & $4.9(\%)$ \\
antiarrhythmic & $0.9(\%)$ & $1.1(\%)$ \\
\hline & & $4.9(\%)$ \\
\hline & & \\
\hline
\end{tabular}

Table 7 The blood pressure responses to nifedipine and placebo in patients with isolated systolic hypertension (visit $18=4$ years treatment)

\begin{tabular}{lcccc}
\hline & $\begin{array}{c}\text { Nifedipine } \\
\text { SBP }\end{array}$ & $\begin{array}{c}\text { Placebo } \\
\text { SBP }\end{array}$ & $\begin{array}{c}\text { Nifedipine } \\
\text { DBP }\end{array}$ & $\begin{array}{c}\text { Placebo } \\
D B P\end{array}$ \\
\hline Visit 0 & $n=1145$ & $n=1158$ & $n=1145$ & $n=1158$ \\
Mean & $148.9 \pm 10.5$ & $150.1 \pm 11.1$ & $79.0 \pm 5.7$ & $79.1 \pm 6.0$ \\
& & & & \\
Visit 18 & $n=933$ & $n=930$ & $n=933$ & $n=930$ \\
Mean & $136.3 \pm 16.5$ & $142.3 \pm 17.7$ & $75.4 \pm 9.1$ & $78.5 \pm 9.0$ \\
Mean difference & $-12.5 \pm 16.9$ & $-7.8 \pm 18.7$ & $-3.8 \pm 9.3$ & $-0.5 \pm 9.6$ \\
\hline
\end{tabular}

the clinical practice of cardiologists and general practitioners.

For example, since the publication of the HOPE trial in $2000^{10}$ there has been a widespread perception that treatment with ACE inhibitor drugs and ramipril, in particular, is selectively beneficial in the treatment of patients with established CAD and that these benefits are not attributable to BP lowering alone. This position has been sustained despite the less convincing findings of the EUROPA ${ }^{11}$ and PEACE $^{12}$ trials. However, since the publication of HOPE, an important additional consideration is that the 'standard' therapy for CAD has become more

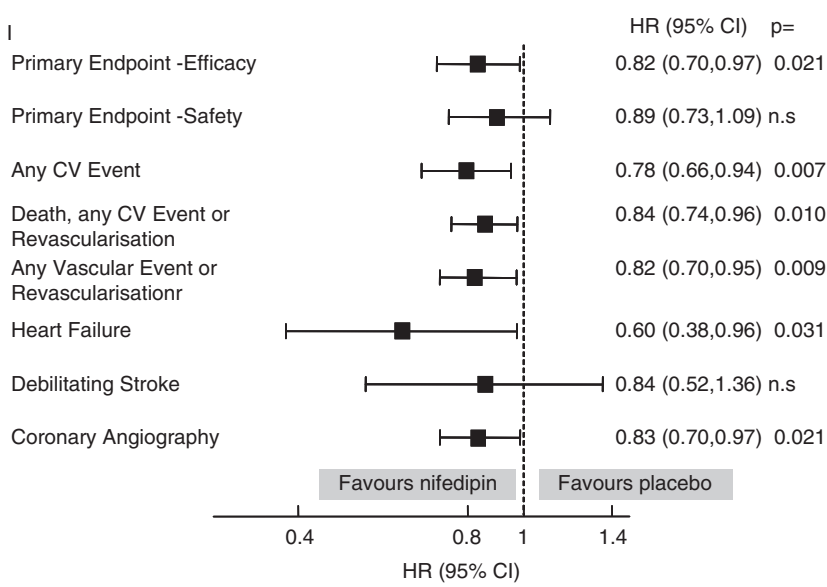

Figure 2 The effect of nifedipine GITS on pre-defined end points in patients with ISH at baseline.

intensive; thus, for example, some of the differences between the results of HOPE and those of PEACE may be explained by more intensive prior drug treatment and better risk factor control in the PEACE population. These baseline differences obviously would reduce the likelihood of a relatively welltreated, low-risk population benefitting from additional ACE inhibitor treatment, as in the PEACE trial. The same interpretation can be applied to the muted effectiveness of the angiotensin receptor blocker, telmisartan, in the TRANSCEND study. ${ }^{13}$

Against this background of evolving and improving treatment combinations, the present ACTION reanalysis afforded the opportunity to assess whether RAS blockade was definitively beneficial or whether or not other treatments, specifically calcium channel blockade with nifedipine GITS, might offer additional benefit in the subgroup of patients who were already receiving 'best practice', 'intensive' treatment including RAS blockade (that is an ACE inhibitor and/or angiotensin receptor blocker) at the start of the trial (baseline). The results of this further analysis identified that additional prognostic benefit could be derived from the addition of nifedipine GITS. These benefits were associated not only with end points that have been shown earlier to be predominantly associated with BP reduction, such as heart failure ${ }^{14}$ but also with those that can be attributed to the anti-ischaemic properties of nifedipine (for example, coronary angiography). The overall trend was for greater reductions in all of the end points in the patients receiving the combination of RAS blockade and calcium channel blockade (nifedipine GITS) than for the overall ACTION population, despite a smaller differential BP reduction (Table 4). Thus, there is evidence to suggest that a long-acting dihydropyridine CCB (nifedipine GITS) may offer prognostic benefit in addition to the symptomatic benefit, which is acknowledged in treatment guidelines. ${ }^{15}$ 
68

These findings in stable but 'high risk' CAD (that is 'secondary' prevention) are compatible with those of two recent outcome studies in hypertension (that is 'primary' prevention). The Anglo-Scandinavian Cardiac Outcomes Trial (ASCOT) compared a CCB/ACE inhibitor (amlodipine/perindopril) regimen with a $\beta$ blocker/diuretic (atenolol/bendroflumethazide) regimen and was stopped early on the advice of the data safety monitoring board. ${ }^{16}$ This decision was largely founded on the significant benefits associated with the CCB/ACE-I that were apparent for almost all of the secondary end points: total CV events and procedures, all coronary events, fatal and non-fatal stroke, CV mortality and total mortality were all significantly reduced. The ACCOMPLISH trial was a randomized, double blind comparison of antihypertensive treatment with the ACE inhibitor benazepril combined with either the CCB amlodipine or the diuretic hydrochlorothiazide. ${ }^{17}$ The group treated with the ACE inhibitor-CCB combination had a relative risk reduction of $\sim 20 \%$ in the primary end point, which was a composite of morbidity and mortality from CV causes. The secondary end point of death from CV causes and non-fatal myocardial infarction and stroke showed a similar benefit. In both ASCOT and ACCOMPLISH there were imbalances in BP control favouring the CCB-based regimens but in both cases the authors provided evidence to suggest that these pressure differences could not account for the observed benefits. ${ }^{16,17}$

The outcome benefits of treatment with dihydropyridine CCBs were obviously established in a number of randomized placebo-controlled trials in hypertensive patients: these included STONE, ${ }^{18}$ SYSTEUR $^{19}$ and SYST-CHINA. ${ }^{20}$ The outcome benefits of nifedipine GITS were specifically confirmed in INSIGHT in which there was no difference in the primary composite end point in comparison with co-amilozide. ${ }^{6}$ In addition to lowering BP, however, and before the publication of the ACTION results, calcium channel blocking drugs (CCBs were recognized treatments for the symptoms of angina pectoris and were widely used for this indication. The ACTION trial was designed and conducted in response to the debate in the 1990s about the safety of CCBs, ${ }^{21,22}$ particularly in patients with CAD, and it aimed to assess the effect of nifedipine GITS on clinical outcomes in patients with stable angina (regardless of the BP level at baseline). A previous retrospective analysis from ACTION confirmed that the benefits of nifedipine GITS were particularly apparent in patients with both CAD and hypertension and highlighted the importance of BP control. ${ }^{8}$ This previous analysis did not address the specific issue of systolic hypertension but it is perhaps indicative of the perception by cardiologists of the importance of $\mathrm{BP}$ control that 'best' practice (albeit from more than a decade ago) permitted $52 \%$ of patients to have $\mathrm{BP}$ $>140 / 90 \mathrm{mmHg}$. These present results not only reinforce the previous observation that $\mathrm{BP}$ reduction and BP control are important in patients with angina but also extend this observation particularly to patients with ISH (or persistent ISH despite prior antihypertensive drug treatment). The main finding is that nifedipine GITS significantly reduced the incidence of the combined end points and that these end point reductions were greater in the ISH subgroup than those observed in the whole ACTION trial population, despite a similar reduction in BP. These present findings are entirely consistent with another analysis that indicated that the benefits of nifedipine GITS can be attributed both to its BP lowering effect and to its anti-anginal properties. ${ }^{14}$ The findings are also consistent with those earlier studies with dihydropyridine CCBs, which focused on ISH. ${ }^{18-20}$ The analysis has not specifically addressed the relationship between $\mathrm{BP}$ reduction and the risk of $\mathrm{CV}$ events but there was no evidence of any deleterious effects of BP lowering in these patients with CAD and ISH and nothing to support the concept of a J-shaped relationship between $\mathrm{BP}$ reduction and the risk of CV events. ${ }^{23,24}$

In conclusion, the present analyses show that the addition of nifedipine GITS to the treatment regimen of patients with symptomatic CAD who were already receiving ACE inhibitors and/or angiotensin receptor blockers results in a significant reduction of CV morbidity. The interpretation of these analyses must obviously be cautious as it is based on subgroup analyses that effectively break the randomization of the original study. Nonetheless, the treatment groups in both analyses were well matched with no statistical differences in either their demographic features (Tables 1 and 5) or their active treatments at baseline (Tables 2 and 6). This, combined with the fact that there were no systematic differences between the groups, leads to the reasonable conclusion that the $\mathrm{CV}$ risk did not differ between the groups and that the addition of the long-acting CCB, nifedipine GITS, was effective not only in improving $\mathrm{BP}$ control but also in reducing major vascular events. These benefits were seen even in patients who were already treated with ACE inhibitors and/or angiotensin receptor blockers and were particularly apparent in patients with poorly controlled systolic BP.

It is well established that as an initial management approach, optimal medical therapy without routine PCI can be implemented safely in the majority of patients with stable CAD. ${ }^{25}$ Furthermore, time trend analyses show a compelling need for more effective management of risk factors in patients with coronary heart disease. ${ }^{26}$ Thus, there is a clear message of practical clinical importance for the 'best practice' treatment of angina: 'reliance' on RAS blockade may be misplaced and greater attention should be directed towards control of BP (and particularly systolic BP) by means, if necessary, of combinations of $\mathrm{BP}$ lowering drugs. 
What is known about this topic

- The treatment of stable coronary artery disease (CAD) is largely founded on established practice rather than evidence-based medicine derived from definitive outcome studies. Systematic survey show a compelling need for more effective management of risk factors in patients with coronary heart disease. ${ }^{26}$

What this study adds

- The placebo-controlled ACTION (A Coronary disease Trial Investigating Outcome with Nifedipine GITS) trial examined treatment effects on clinical outcomes in patients with stable symptomatic CAD. The principal conclusions were that nifedipine GITS was not only is safe in patients with stable symptomatic coronary disease but also significantly reduces the occurrence of new overt heart failure and the need for coronary interventions. ${ }^{7}$

- These retrospective analyses of the ACTION database provides additional evidence that nifedipine GITS, in the treatment of symptomatic CAD patients, is effective not only for improving blood pressure control but also for reducing major vascular events in those patients (a) who were already receiving treatment with renin angiotensin system blocking drugs and (b) who had isolated systolic hypertension.

\section{Conflict of interest}

The authors declare no conflict of interest.

\section{Acknowledgements}

The analysis was supported by an unrestricted grant from Bayer Schering Pharma.

\section{References}

1 Lopez AD, Mathers CD, Ezzati M, Jamison DT, Murray CJ. Global and regional burden of disease and risk factors, 2001: systematic analysis of population health data. Lancet 2006; 367(9524): 1747-1757.

2 Lawes CM, Vander Hoorn S, Rodgers A, International Society of Hypertension. Global burden of blood-pressurerelated disease, 2001. Lancet 2008; 371(9623): 1513-1518.

3 Lopez AD, Mathers CD. Measuring the global burden of disease and epidemiological transitions: 2002-2030. Ann Trop Med Parasitol 2006; 100(5-6): 481-499.

4 Mancia G, De Backer G, Dominiczak A, Cifkova R, Fagard R, Germano G et al., Management of Arterial Hypertension of the European Society of Hypertension. European Society of Cardiology. 2007 Guidelines for the management of arterial hypertension: the task force for the management of arterial hypertension of the European Society of Hypertension (ESH) and of the European Society of Cardiology (ESC). J Hypertens 2007; 25(6): 1105-1187.

5 Williams B, Lindholm LH, Sever P. Systolic pressure is all that matters. Lancet 2008; 371(9631): 2219-2221.

6 Brown MJ, Palmer CR, Castaigne A, de Leeuw PW, Mancia G, Rosenthal T et al. Morbidity and mortality in patients randomised to double-blind treatment with a long-acting calcium-channel blocker or diuretic in the International Nifedipine GITS study; Intervention as a Goal in Hypertension Treatment (INSIGHT). Lancet 2000; 356: 366-372.

7 Poole-Wilson PA, Lubsen J, Kirwan BA, van Dalen FJ, Wagener G, Danchin N et al. Effect of long acting nifedipine on mortality and cardiovascular morbidity in patients with stable angina requiring treatment (ACTION trial): randomised controlled trial. Lancet 2004; 364: 849-857.

8 Lubsen J, Wagener G, Kirwan BA, de Brouwer S, Poole-Wilson PA, ACTION (A Coronary disease Trial Investigating Outcome with Nifedipine GITS) investigators. Effect of long-acting nifedipine on mortality and cardiovascular morbidity in patients with symptomatic stable angina and hypertension: the ACTION trial. J Hypertens 2005; 23(3): 641-648.

9 Lubsen J, Poole-Wilson PA, Pocock SJ, van Dalen FJ, Baumann J, Kirwan BA et al. Design and current status of ACTION: a coronary disease trial investigating outcome with Nifedipine GITS. Eur Heart $J$ 1998; 19(suppl 1): I20-I32.

10 The Heart Outcomes Prevention Evaluation Study Investigators. Effects of an angiotensin-convertingenzyme inhibitor, ramipril, on cardiovascular events in high-risk patients. $N$ Engl J Med 2000; 342: 145-153.

11 Fox KM. Efficacy of perindopril in reduction of cardiovascular events among patients with stable coronary artery disease: randomised, double-blind, placebo-controlled, multicentre trial (the EUROPA study). Lancet 2003; 362: 782-788.

12 Braunwald E, Domanski MJ, Fowler SE, Geller NL, Gersh BJ, Hsia J et al., PEACE Trial Investigators. Angiotensin-converting-enzyme inhibition in stable coronary artery disease. $N$ Engl J Med 2004; 351(20): 2058-2068.

13 The Telmisartan Randomised AssessmeNt Study in ACE iNtolerant subjects with cardiovascular Disease (TRANSCEND) Investigators. Effects of the angiotensin-receptor blocker telmisartan on cardiovascular events in high-risk patients intolerant to angiotensinconverting enzyme inhibitors: a randomised controlled trial. Lancet 2008; 372: 1174-1183.

14 Lubsen J, Voko Z, Poole-Wilson PA, Kirwan BA, de Brouwer S, ACTION (A Coronary disease Trial Investigating Outcome with Nifedipine GITS) investigators. Blood pressure reduction in stable angina by nifedipine was related to stroke and heart failure reduction but not to coronary interventions. J Clin Epidemiol 2007; 60(7): 720-726.

15 The Task Force on the Management of Stable Angina Pectoris of the European Society of Cardiology. Guidelines on the management of stable angina pectoris: full text. Eur Heart J 2006; 27: 1341-1381.

16 Dahlöf B, Sever PS, Poulter NR, Wedel H, Beevers DG, Caulfield $\mathrm{M}$ et al. Prevention of cardiovascular events with an antihypertensive regimen of amlodipine adding perindopril as required versus atenolol adding bendroflumethiazide as required, in the Anglo-Scandinavian Cardiac Outcomes Trial-Blood Pressure Lowering Arm (ASCOT-BPLA): a multicentre randomised controlled trial. Lancet 2005; 366: 895-906.

17 Jamerson K, Weber MA, Bakris GL, Dahlöf B, Pitt B, Shi $\mathrm{V}$ et al. Benazepril plus amlodipine or hydrochlorothiazide for hypertension in high-risk patients. $N$ Engl J Med 2008; 359: 2417-2428.

18 Gong L, Zhang W, Zhu Y, Zhu J, Kong D, Page V et al. Shanghai trial of nifedipine in the elderly (STONE). J Hypertens 1996; 14(10): 1237-1245. 
19 Staessen JA, Fagard R, Thijs L, Celis H, Arabidze GG, Birkenhäger WH, et al., for the Systolic Hypertension in Europe (Syst-Eur) Trial Investigators. Randomised double-blind comparison of placebo and active treatment for older patients with isolated systolic hypertension. Lancet 1997; 350: 757-764.

20 Wang JG, Staessen JA, Gong L, Liu L. Chinese trial on isolated systolic hypertension in the elderly. Systolic Hypertension in China (Syst-China) Collaborative Group. Arch Intern Med 2000; 160(2): 211-220.

21 Horton R. Spinning the risks and benefits of calcium antagonists. Lancet 1995; 346: 586-587.

22 Opie LH. Risks and benefits of calcium antagonists. Lancet 1995; 346: 961.

23 Cruickshank JM, Thorp JM, Zacharias FJ. Benefits and potential harm of lowering high blood pressure. Lancet 1987; 1: 581-584.

24 Messerli FH, Mancia G, Conti CR, Hewkin AC, Kupfer S, Champion A et al. Dogma disputed: can aggressively lowering blood pressure in hypertensive patients with coronary artery disease be dangerous? Ann Intern Med 2006; 144(12): 884-893.

25 Boden WE, O'Rourke RA, Teo KK, Hartigan PM, Maron DJ, Kostuk WJ et al. Optimal medical therapy with or without PCI for stable coronary disease. New Engl J Med 2007; 356: 1503-1516.

26 Kotseva K, Wood D, De Backer G, De Bacquer D, Pyörälä K, Keil U, EUROASPIRE Study Group. Cardiovascular prevention guidelines in daily practice: a comparison of EUROASPIRE I, II, and III surveys in eight European countries. Lancet 2009; 373: 929-940.

(c) This work is licensed under the Creative Commons Attribution-NonCommercialNo Derivative Works 3.0 Unported License. To view a copy of this license, visit http://creativecommons. org/licenses/by-nc-nd/3.0/ 